6. Tunis SR, Hayward RS, Wilson MC, et al. Internists' attitudes about clinical practice guidelines. Ann Intern Med 1994;120:956-963.

7. Woolf SH. Practice guidelines: a new reality in medicine, 3 : impact on patient care. Arch Intern Med 1993;153:2646-2655.
8. Joint Commission on Accreditation of Healthcare Organizations. Surveillance, prevention, and control of infections. Joint Commission on Accreditation of Healthcare Organization's 1995 Accreditation Manual for Hospitals. Oakbrook Terrace, IL: JCAHO; 1994:437-450.

\title{
Safety Devices Reduce Injuries
}

\section{by Gina Pugliese, RN, MS Medical News Editor}

Dr. Mary Chamberland and colleagues from the $\mathrm{CDC}$ recently reported the findings of a study that showed a significant reduction in percutaneous injuries during phlebotomy when safety devices were used.

Baseline surveillance of needlestick injuries in six hospitals revealed that the proportion of needlestick injuries varied significantly by occupation: $89 \%$ for phlebotomists, $65 \%$ for nurses, $40 \%$ for medical students, and $32 \%$ for residents. Following a period of baseline surveillance, the hospitals implemented safety devices that required user activation of the safety feature (eg, resheathable or bluntable needles for vacuum tube blood collec- tion needles and winged steel needles). From January 1993 through November 1994, percutaneous injury rates per 100,000 phlebotomy procedures (adjusted for underreporting and use of safety devices) were reduced $41 \%$, from 3.9 with standard devices to 2.3 with safety devices; for vacuum tube blood collection needles, rates were reduced $82 \%$ from 3.4 to 0.6 , and for winged steel needles, rates were reduced $16 \%$ from 4.3 to 3.6 per 100,000 procedures.

An inventory of the sharps disposal containers found that safety devices were not activated approximately $25 \%$ of the time.

Of the 27 percutaneous injuries associated with safety devices, 15 (56\%) occurred before activation of the safety feature was appropriate, 5
(18\%) during activation, and 1 (4\%) after activation.

The researchers concluded that safety devices may prevent at least $40 \%$ of percutaneous injuries during phlebotomy. However, underreporting of injuries and variations in use and activation of safety devices also must be considered when evaluating the impact of the safety device.

FROM: Chamberland M, Short $\mathrm{L}$, Srivastava K, et al. Implementation, impact, and compliance with use of safety devices to reduce percutaneous injuries during phlebotomies. In: Abstracts from the Conference on Bloodborne Infections: Occupational Risks and Prevention; June 8-9, 1995; Paris, France. 